\title{
Resenha
}

\section{Psiquiatria para estudantes de medicina}

PSIQUIATRIA

PARA ESTUDANTES DE MEDICINA

\author{
Alfredo Cataldo Neto, Gabriel Chittó \\ Gauer e Nina Rosa Furtado (orgs.) \\ Porto Alegre, EDIPUCRS, 2003
}

\author{
Miguel R. Jorge*
}

O livro Psiquiatria para estudantes de medicina, que tem como organizadores Alfredo Cataldo Neto, Gabriel José Chittó Gauer e Nina Rosa Furtado, representa, a nosso ver, o primeiro esforço de produção de um tratado de psiquiatria no Brasil.

Duzentos e cinqüenta profissionais, quase todos trabalhando ou formados no Rio Grande do Sul, lograram produzir um livro de importância e aplicabilidade nacional. Afinal, se diferenças existem na expressão de quadros psiquiátricos e nas características da relação médico-paciente, infelizmente elas estão mais relacionadas a contextos clínicos e socioeconômicos distintos do que propriamente à diversidade cultural das regiões do país.

Distribuem-se, nas quase 1.000 páginas do livro, cerca de 160 capítulos dedicados particularmente à psicologia médica e à psiquiatria clínica, assuntos de grande interesse para a imensa maioria dos estudantes de medicina que, mesmo não vindo a se especializar na área, estarão expostos aos aspectos e necessidades psicológicas de
* Professor adjunto, livre-docente e chefe da disciplina de Psiquiatria Clínica. Coordenador do Programa de Pós-Graduação em Psiquiatria, Psicologia Médica e Saúde Mental, Escola Paulista de Medicina, Universidade Federal de São Paulo (EPM-UNIFESP). pacientes gerais e freqüentemente em contato com pacientes portadores de transtornos mentais e da personalidade.

Tanto no que diz respeito às bases da psiquiatria e sua inter-relação com outras ciências, como no que concerne aos processos etiológicos e diagnósticos e às intervenções terapêuticas recomendadas para os diferentes tipos de transtornos mentais, os organizadores deste livro nitidamente buscaram e alcançaram um harmonioso equilíbrio entre aspectos biológicos e aqueles de natureza psicossocial.

A Parte I apresenta as bases da psiquiatria, desde seus aspectos históricos e aspectos psicodinâmicos de importância para o entendimento do funcionamento psíquico, até os possíveis determinantes dos diversos transtornos mentais.

Em pouco mais de 150 páginas, as Partes II, III e IV esmiúçam o que de mais fundamental pode conhecer o futuro médico sobre os determinantes da relação médicopaciente em diferentes fases da vida dos pacientes e outros aspectos de importância na psicologia médica.

Já na Parte V, diversos autores apresentam os componentes de uma boa anamnese psiquiátrica, complementada pela avaliação neurológica e pelo uso de testes psicológicos e 
de escalas padronizadas de avaliação psiquiátrica.

Certamente a seção mais longa, quase um livro dentro do outro, é a dedicada aos transtornos mentais, com suas 340 páginas. São 58 capítulos que iniciam por apresentar uma classificação dos transtornos mentais e terminam por abordar quadros próprios da infância e adolescência. Os diversos tipos de transtornos mentais e da personalidade são abordados de forma clássica pelos autores de cada capítulo, que apresentam dados históricos, epidemiológicos, etiológicos, de caracterização clínica, diagnósticos e importantes para o diagnóstico diferencial, terapêuticos e evolutivos.

A Parte VII oportunamente apresenta os principais tipos de emergências psiquiátricas, com os quais os futuros médicos de qualquer especialidade certamente se depararão pelo menos nas fases iniciais de suas carreiras, quando é bastante comum estarem de plantão em serviços de emergência ou sendo chamados a enfermarias de hospitais gerais onde, na maioria das vezes, não há um psiquiatra de plantão. Boa parte desta seção é dirigida aos diversos aspectos que envolvem a questão do suicídio.

A seção sobre abordagens terapêuticas envolve as diferentes classes de medicamentos utilizados no tratamento dos transtornos mentais, bem como outras abordagens biológicas e diferentes técnicas psicoterápicas. Em um livro voltado para estudantes de medicina, esta seção deve ser tomada apenas como uma referência para uma abordagem terapêutica de casos mais simples ou para o controle imediato de situações de urgência psiquiátrica, bem como para uma compreensão geral do que se pode oferecer em termos de manejo psicológico às diferentes demandas colocadas por distintos transtornos ou por um mesmo tipo de transtorno em pessoas de constituições psicológicas diferentes.
A Parte IX aborda a inter-relação da psiquiatria com outras ciências, particularmente com outras especialidades médicas e a terapia ocupacional, enfermagem e fisioterapia, além da arte e antropologia. Alguns tópicos de psiquiatria forense e aspectos relacionados à supervisão, bem como a listagem de alguns sites de interesse psiquiátrico na internet são apresentados nas duas últimas seções do livro.

Enfim, trata-se de uma obra "de fôlego", bastante abrangente e completa. Como já está disponível nos principais revendedores de livros médicos há cerca de 1 ano, certamente seus organizadores estão recolhendo sugestões tanto do seu público-alvo - os estudantes de medicina - quanto dos especialistas em psiquiatria, que permitirão o aperfeiçoamento deste livro em suas esperadas re-edições futuras. Creio que, quando de uma revisão da presente publicação, uma uniformização na extensão e no nível de profundidade dos diversos capítulos possa ser alvo de atenção de seus organizadores.

A ampla difusão que o presente livro possa ter entre os professores de psiquiatria e alunos de medicina das faculdades e universidades brasileiras certamente contribuirá para o aprimoramento da formação desses profissionais e se refletirá na qualidade da assistência prestada aos portadores de transtornos mentais em todas as regiões do país.

Title: Review of the book entitled Psiquiatria para estudantes de medicina

Título: Reseña del libro Psiquiatria para estudantes de medicina

E-mail: migueljorge@terra.com.br

Copyright (C) Revista de Psiquiatria do Rio Grande do Sul - SPRS 